\title{
The correlation between neonatal vitamin D levels and the risk of childhood asthma attacks
}

\author{
Wenlin Li $^{1 \#}$, Jin Zhou ${ }^{2 \#}$, Shen Liu ${ }^{2}$, Kaihui Xing ${ }^{1}$, Ling Yang ${ }^{1}$, Lihua Zhong ${ }^{1}$, Qiuli Chen ${ }^{2}$, Wei Zhang ${ }^{1}$ \\ ${ }^{1}$ Department of Neonatology, Haikou Hospital of The Maternal And Child Health, Haikou, China; ${ }^{2}$ Department of Pediatrics, Haikou Hospital of \\ Maternal and Child Health, Haikou, China \\ Contributions: (I) Conception and design: W Li, J Zhou, W Zhang; (II) Administrative support: S Liu, K Xing, L Yang; (III) Provision of study \\ materials or patients: L Zhong, Q Chen, W Zhang; (IV) Collection and assembly of data: All authors; (V) Data analysis and interpretation: W Li, J \\ Zhou, W Zhang; (VI) Manuscript writing: All authors; (VII) Final approval of manuscript: All authors. \\ "These authors contributed equally to this work. \\ Correspondence to: Wei Zhang. Department of Neonatology, Haikou Hospital of The Maternal And Child Health, 75 Longkun South Road, Haikou \\ City, Hainan 570206, China. Email: zhangwei7195@163.com.
}

Background: To explore the correlation between neonatal vitamin D levels and the risk of asthma in children aged 3-9 years.

Methods: A total of 1,534 subjects were selected, and clinical and laboratory test data of all subjects were collected at birth, including 25-hydroxyvitamin D3 [25(OH)D3] levels, gender, season of birth, birth weight; whether delivery was premature, cesarean section, or primipara; and parental details including maternal age, ethnicity, level of education, history of smoking, and history of maternal or paternal asthma. The level of $25(\mathrm{OH}) \mathrm{D} 3$ was used as a continuous variable to analyze its correlation with the risk of asthma using the Cox proportional regression model. In addition, subjects were divided into four groups according to their 25(OH) D3 quartiles, and the first quantile group was used as a reference to analyze the risk of asthma in the other groups. Further subgroup analysis was conducted according to the patients' gender and birth season.

Results: Among the 1,534 subjects included, there were 107 cases in the asthma-affected group and 1,427 cases in the normal control group. Compared with the control group, the level of $25(\mathrm{OH}) \mathrm{D} 3$ in the asthma group was significantly lower $(\mathrm{P}=0.03)$, the mother's education level was lower $(\mathrm{P}=0.002)$, but the preterm birth rate, cesarean section rate, and parental asthma prevalence rate were significantly higher (all $\mathrm{P}<0.05$ ). When the neonatal 25(OH)D3 was divided into quartiles to perform a categorical variable analysis, we found that compared with the first quantile (Q1, 0.0-25.1 mmol/L), the risk of asthma in Q4 was reduced by $50 \%$ (HR=0.50, 95\% CI: 0.38-0.76). The second quantile group (Q2) and the third quantile group (Q3) showed no significant difference in the risk of disease compared with Q1 but showed a trend of decreasing risk as the quantile group increased (the trend $\mathrm{P}$ values were both $<0.05$ ). This correlation was still valid when a stratified analysis was made based on gender and birth season.

Conclusions: There is a significant correlation between a reduced vitamin D level in newborns and the subsequent risk of asthma in children aged 3-9 years. Moreover, the level of vitamin D is an independent risk factor for childhood asthma.

Keywords: Newborns; vitamin D; children; asthma

Submitted Feb 04, 2021. Accepted for publication Apr 20, 2021.

doi: $10.21037 / \mathrm{tp}-21-92$

View this article at: http://dx.doi.org/10.21037/tp-21-92 


\section{Introduction}

Asthma is a chronic respiratory disease that involves the immune system and the respiratory system. It usually occurs in infants and young children, and it is estimated that the global incidence of asthma in children aged 6-7 years is $9.4 \%$ (1). The age of onset of asthma is usually relatively young, indicating that the environment during pregnancy may play an important role in the onset of the disease (2). Asthma is a heterogeneous disease with many different phenotypes. Early childhood asthma and allergic asthma are more common in boys, and girls' asthma attacks tend to increase around puberty $(3,4)$.

Vitamin D is a fat-soluble vitamin and secretory hormone, which is mainly produced when the skin receives ultraviolet radiation from sunlight, and it can also be obtained from a few dietary sources (5). The source of vitamin $\mathrm{D}$ for the fetus is completely dependent on the mother and is transmitted through the placenta in the form of vitamin 25 (D) (6). Vitamin D deficiency is common in pregnant women (6) and, importantly, is associated with adverse health outcomes for the mother and her offspring (7-9). In particular, vitamin $\mathrm{D}$ deficiency during pregnancy can affect the lung and immune function of the offspring and can promote the development of childhood asthma $(10,11)$.

A joint analysis of two randomized controlled trials found that prenatal vitamin D supplementation can significantly reduce the risk of asthma by $26 \%(12-14)$. However, previous observational studies examining prenatal or neonatal $25(\mathrm{OH}) \mathrm{D}$ status have not found an association with asthma risk (15-18). This may be due to the small sample size or the short follow-up time. This study aims to explore the impact of neonatal vitamin $\mathrm{D}$ levels on the incidence of asthma in children aged 3-9 years in a large population sample. We present the following article in accordance with the MDAR checklist (available at http:// dx.doi.org/10.21037/tp-21-92).

\section{Methods}

\section{Research subjects}

Newborns in our hospital from January 2008 to January 2011 were selected. Inclusion criteria were as follows: (I) vitamin $\mathrm{D}$ was measured and fully recorded at birth; (II) complete and relevant clinical and demographic data were registered at birth; (III) Medical records of onset of asthma between the ages of 3-9 years were available. Based on these criteria, a total of 1,534 subjects were included.
All procedures performed in this study involving human participants were in accordance with the Declaration of Helsinki (as revised in 2013). Parental informed consent was obtained on behalf of all subjects, and the study was approved by the Research Ethics Committee of Haikou Hospital of The Maternal And Child Health.

\section{Data collection}

The clinical and laboratory test data of all subjects at birth were collected, including $25(\mathrm{OH}) \mathrm{D}_{3}$ levels, gender, birth season, and birth weight; whether delivery was premature, cesarean section, or primipara; and parental details including maternal age, ethnicity, level of education, history of smoking, and history of maternal or paternal asthma.

Vitamin D levels were evaluated by $3.2 \mathrm{~mm}$ punch measurement of $25(\mathrm{OH}) \mathrm{D}_{2}$ and $25(\mathrm{OH}) \mathrm{D}_{3}$. An equivalent serum analysis was used by the laboratory to evaluate vitamin D (19). The liquid chromatography-tandem mass spectrometry (LC-MS) method was used for the sample preparation and analysis (20), which was calibrated and controlled by a PerkinElmer MSMS kit (PerkinElmer, USA). The intra- and inter-assay coefficients of variation for $25(\mathrm{OH}) \mathrm{D}_{3}$ were $7-12 \%$ and $7-20 \%$, respectively, and for $25(\mathrm{OH}) \mathrm{D}_{2}$ were $4-8 \%$ and $9-18 \%$, respectively. The lower limit of quantification (LLOQ) of $25(\mathrm{OH}) \mathrm{D}_{3}$ was $4 \mathrm{nmol} / \mathrm{L}$, and the LLOQ of $25(\mathrm{OH}) \mathrm{D}_{2}$ was $3 \mathrm{nmol} / \mathrm{L}$. To correct the $25(\mathrm{OH}) \mathrm{D}_{3}$ concentration to reflect the bioequivalent concentration of serum, the following formula was used: Serum $25(\mathrm{OH}) \mathrm{D}_{3} \mathrm{nmol} / \mathrm{L}=\mathrm{DBSS} 25(\mathrm{OH}) \mathrm{D}_{3} \mathrm{nmol} / \mathrm{L} \times 1 /$ (1-0.61), where 0.61 was the red blood cell pressure integral of capillary blood.

\section{Statistical methods}

SAS 9.4 software (SAS, United States) was used for the statistical analysis. The subjects were allocated to an asthma group or a normal control group based on whether they had developed asthma between the ages of 3-9 years. Categorical variables are displayed as the number of cases (percentage), and continuous variables are displayed as mean \pm standard deviation or median (interquartile range). The differences between groups were compared by the $\chi^{2}$ test or Kruskal-Wallis test. $25(\mathrm{OH}) \mathrm{D}_{3}$ was used as a continuous variable to analyze its correlation with the risk of asthma by implementing the Cox proportional regression model. The subjects were divided into four groups according to their $25(\mathrm{OH}) \mathrm{D}_{3}$ quartiles, and the first quantile group was 
Table 1 Comparison of various indicators between the asthma and control groups

\begin{tabular}{|c|c|c|c|}
\hline & Asthma group & Control group & $P$ value \\
\hline $25(\mathrm{OH}) \mathrm{D}_{3}(\mathrm{nmol} / \mathrm{L})$ median (interquartile range) & $23(14-35)$ & $29(17-40)$ & 0.03 \\
\hline Male, n (\%) & $47(43.9)$ & $632(44.3)$ & $<0.01$ \\
\hline Season of birth & & & 0.15 \\
\hline February to July & $53(50)$ & $756(53)$ & \\
\hline Premature delivery, n (\%) & $7(7)$ & $100(7)$ & 0.03 \\
\hline Cesarean section, $\mathrm{n}(\%)$ & $14(13)$ & $143(10)$ & 0.04 \\
\hline Birth weight $(\mathrm{g})$ & 3387 (632) & $3499(532)$ & 0.58 \\
\hline Maternal ethnicity (Han), n (\%) & $97(91)$ & $1230(91)$ & 0.98 \\
\hline Maternal education (above high school), n (\%) & $75(70)$ & $1085(76)$ & $<0.01$ \\
\hline Maternal smoking, $\mathrm{n}(\%)$ & $30(28)$ & $314(22)$ & 0.04 \\
\hline Maternal asthma, n (\%) & $9(8)$ & $71(5)$ & $<0.01$ \\
\hline Paternal asthma, n (\%) & $6(6)$ & $43(3)$ & $<0.01$ \\
\hline
\end{tabular}

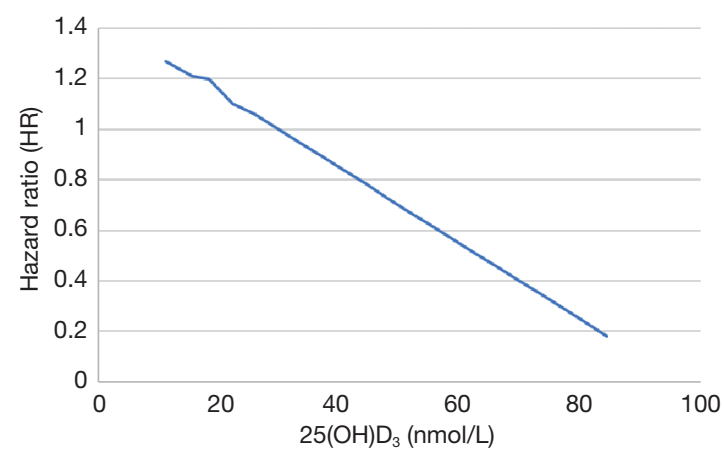

Figure 1 The correlation between neonatal 25(OH)D3 concentration and asthma risk in children aged 3-9 years.

used as a reference to analyze the risk of asthma in the other groups. Further subgroup analysis was conducted according to the patients' gender and birth season.

\section{Results}

Comparison of various indicators between the asthma group and the control group

Among the 1,534 subjects included, there were 107 cases in the asthma group and 1,427 cases in the normal control group. Compared with the control group, the level of $25(\mathrm{OH}) \mathrm{D}_{3}$ in the asthma group was significantly lower $(\mathrm{P}=0.03)$, the mother's education level was lower $(\mathrm{P}=0.002)$, but the preterm birth rate, cesarean section rate, and parental asthma prevalence rate were significantly higher (all $\mathrm{P}<0.05$ ). There was no significant difference between the two groups in terms of birth season, birth weight, primiparity rate, maternal age, and maternal ethnicity ( $\mathrm{P}>0.05)$, as shown in Table 1 .

\section{The correlation between neonatal $25(\mathrm{OH}) \mathrm{D}_{3}$ and the risk of asthma in children aged 3-9 years}

When neonatal $25(\mathrm{OH}) \mathrm{D}_{3}$ was analyzed as a continuous variable, we found that the risk of asthma in children aged 3-9 years was almost linearly related to the concentration of $25(\mathrm{OH}) \mathrm{D}_{3}$ in newborns, as shown in Figure 1. When the neonatal $25(\mathrm{OH}) \mathrm{D}_{3}$ was divided into quartiles to perform a categorical variable analysis, compared with the first quantile (Q1, 0.0-25.1 mmol/L) and when uncorrected (model 1), the risk of asthma in the fourth quartile $(\mathrm{Q} 4$, $47.8-110.8 \mathrm{mmol} / \mathrm{L}$ ) in children aged $3-9$ years was reduced 
Table 2 Cox proportional analysis of asthma risk in children aged 3-9 years

\begin{tabular}{lccccc}
\hline & $\begin{array}{c}\text { Q1 }(0.0-25.1 \mathrm{mmol} / \mathrm{L}) \\
\mathrm{HR}(95 \% \mathrm{Cl})\end{array}$ & $\begin{array}{c}\text { Q2 }(25.1-32.3 \mathrm{mmol} / \mathrm{L}) \\
\mathrm{HR}(95 \% \mathrm{Cl})\end{array}$ & $\begin{array}{c}\text { Q3 }(32.3-47.8 \mathrm{mmol} / \mathrm{L}) \\
\mathrm{HR}(95 \% \mathrm{Cl})\end{array}$ & $\begin{array}{c}\text { Q4 }(47.8-110.8 \mathrm{mmol} / \mathrm{L}) \\
\mathrm{HR}(95 \% \mathrm{Cl})\end{array}$ & $\begin{array}{c}\text { Trend P values } \\
\text { Model 1 }\end{array}$ \\
1 (ref) & $0.95(0.73,1.21)$ & $0.96(0.73,1.24)$ & $0.62(0.47,0.81)$ \\
Model 2 & 1 (ref) & $0.98(0.76,1.27)$ & $0.92(0.66,1.24)$ & $0.54(0.38,0.76)$ & 0.003 \\
Model 3 & 1 (ref) & $0.91(0.56,1.28)$ & $0.81(0.57,1.13)$ & $0.50(0.36,0.74)$ & 0.002 \\
\hline
\end{tabular}

by $38 \%$ (HR $=0.62,95 \%$ CI: $0.47-0.81)$. When gender, birth season, history of maternal asthma, and history of paternal asthma were adjusted (model 2), the risk of asthma in Q4 was reduced by $46 \%$ (HR $=0.54,95 \%$ CI: $0.38-0.76$ ). When premature delivery, cesarean section, birth weight, and maternal education level were further adjusted (model 3 ), the risk of asthma in Q4 was reduced by $50 \%$ (HR $=0.50,95 \%$ CI: $0.38-0.76)$. The second quantile group $(\mathrm{Q} 2)$ and the third quantile group (Q3) showed no significant difference in the risk of disease compared with Q1 but showed a trend of decreasing risk as the quantile group increased (the trend $\mathrm{P}$ values were both $<0.05$ ), as shown in Table 2.

\section{Stratified analysis of the relationship between neonatal $25(\mathrm{OH}) \mathrm{D}_{3}$ and the risk of asthma in children aged 3-9 years}

When stratified by gender, we found that in girls, when uncorrected (model 1) and compared to Q1, the asthma risk in Q4 was reduced by $32 \%$ (HR $=0.68,95 \%$ CI: $0.47-0.92$ ). After full adjustment (model 3) and compared with Q1, the risk of asthma in Q4 was reduced by $44 \%$ ( $\mathrm{HR}=0.56,95 \%$ CI: 0.38-0.97). In boys, when unadjusted (model 1), the risk of asthma in Q4 was reduced by 39\% compared to that of Q1 (HR $=0.61,95 \%$ CI: 0.43-0.75). After full adjustment (model 3) and compared with Q1, asthma risk in Q4 was reduced by $42 \%$ (HR $=0.58,95 \%$ CI: $0.43-0.89$ ). Moreover, there was no interaction between neonatal $25(\mathrm{OH}) \mathrm{D}_{3}$ concentration and gender $(\mathrm{P}>0.05)$.

When the stratified analysis was based on the birth season, we found that in children born between August and January, when uncorrected (model 1) and compared with Q1, the risk of asthma in Q4 was reduced by $43 \%$ (HR $=0.57,95 \%$ CI: 0.44-0.74). After full adjustment (model 3) and compared with Q1, the risk of asthma in Q4 was reduced by $52 \%$ (HR $=0.48,95 \%$ CI: $0.35-0.79$ ). In children born between February and July, when uncorrected (model 1), the risk of asthma in Q4 was reduced by $21 \%$ compared with Q1 (HR =0.79, 95\% CI: 0.41-0.98). After full adjustment (model 3) and compared with Q1, the asthma risk of Q4 was reduced by $31 \%(\mathrm{HR}=0.69,95 \% \mathrm{CI}$ : $0.42-0.93)$. Furthermore, there was no interaction between neonatal $25(\mathrm{OH}) \mathrm{D}_{3}$ concentration levels and birth season ( $\mathrm{P}>0.05)$, as shown in Table 3.

\section{Discussion}

This study found that, compared with the lowest quartile of neonatal $25(\mathrm{OH}) \mathrm{D}_{3}$ concentration, neonates in the highest quartile had a significantly lower risk of developing asthma between the ages of 3-9 years, and it still held when the stratified analysis was based on the gender and birth season of the newborn. Therefore, the early detection of low neonatal $25(\mathrm{OH}) \mathrm{D}_{3}$ is of great significance for the prevention and treatment of asthma in children aged 3-9 years.

Research suggests that prenatal vitamin $\mathrm{D}$ concentration is important for fetal lung and immune system development and can reduce the risk of childhood asthma attacks. Previous studies have observed that in mouse models, vitamin $\mathrm{D}$ deficiency in the uterus is associated with the reduction of Lung helper T cell 2 (Th2) and regulatory $\mathrm{T}$ (Treg) cells (19). In the pathogenesis of asthma, Th2 causes airway hyper-responsiveness and remodeling through inflammatory pathways (20). In addition, studies have shown that changes in lung protein expression in newborns are related to maternal vitamin D deficiency (21). In a human clinical study, mothers who were supplemented with 4,400 U/d vitamin D during pregnancy showed a greater increase in the production of pro-inflammatory cytokines than mothers who were supplemented with $400 \mathrm{U} / \mathrm{d}$ vitamin $\mathrm{D}$, and it is known that a stronger cytokine response can reduce respiratory infections. It is suggested that vitamin $\mathrm{D}$ can enhance the immune response, thereby reducing the risk of asthma (22).

Similar to the results of this study, two observational studies found that $25(\mathrm{OH}) \mathrm{D}_{3}$ levels during pregnancy were significantly negatively correlated with the incidence 
Table 3 Stratified analysis of asthma risk in children aged 3-9 years based on gender and birth season

\begin{tabular}{|c|c|c|c|}
\hline & Model $1 \mathrm{HR}(95 \% \mathrm{Cl})$ & Model $2 \mathrm{HR}(95 \% \mathrm{Cl})$ & Model 3 HR (95\% Cl) \\
\hline \multicolumn{4}{|l|}{ Female $(\mathrm{N}=855)$} \\
\hline Q1 (0.0-25.1 mmol/L) & 1 (ref) & 1 (ref) & 1 (ref) \\
\hline Q2 (25.1-32.3 mmol/L) & $0.78(0.58,1.21)$ & $0.98(0.56,1.48)$ & $0.85(0.61,1.38)$ \\
\hline Q3 (32.3-47.8 mmol/L) & $0.96(0.73,1.49)$ & $0.97(0.48,1.56)$ & $0.83(0.44,1.55)$ \\
\hline \multicolumn{4}{|l|}{ Male $(\mathrm{N}=679)$} \\
\hline Q1 (0.0-25.1 mmol/L) & 1 (ref) & 1 (ref) & 1 (ref) \\
\hline Q2 (25.1-32.3 mmol/L) & $0.95(0.59,1.35)$ & $1.15(0.72,1.41)$ & $0.98(0.75,1.25)$ \\
\hline Q3 (32.3-47.8 mmol/L) & $0.92(0.69,1.28)$ & $0.91(0.73,1.38)$ & $0.81(0.56,1.24)$ \\
\hline Q1 (0.0-25.1 mmol/L) & 1 (ref) & 1 (ref) & 1 (ref) \\
\hline Q2 (25.1-32.3 mmol/L) & $0.91(0.62,1.30)$ & $1.03(0.77,1.52)$ & $0.97(0.69,1.56)$ \\
\hline Q3 (32.3-47.8 mmol/L) & $0.76(0.42,1.19)$ & $0.85(0.56,1.23)$ & $0.78(0.48,1.14)$ \\
\hline Q4 (47.8-110.8 mmol/L) & $0.57(0.44,0.74)$ & $0.53(0.38,0.79)$ & $0.48(0.35,0.79)$ \\
\hline \multicolumn{4}{|c|}{ Born February to July (N=809) } \\
\hline Q1 (0.0-25.1 mmol/L) & 1 (ref) & 1 (ref) & 1 (ref) \\
\hline Q2 (25.1-32.3 mmol/L) & $0.92(0.68,1.34)$ & $0.91(0.65,1.35)$ & $0.82(0.58,1.28)$ \\
\hline Q3 (32.3-47.8 mmol/L) & $1.07(0.76,1.53)$ & $0.96(0.68,1.44)$ & $0.93(0.68,1.53)$ \\
\hline
\end{tabular}

of spring asthma in newborns $(23,24)$. A study found that compared to boys with $25(\mathrm{OH}) \mathrm{D}_{3}>50 \mathrm{nmol} / \mathrm{L}$ in the neonatal period, boys with $25(\mathrm{OH}) \mathrm{D}_{3}<50 \mathrm{nmol} / \mathrm{L}$ have a significantly higher risk of asthma at 6 years old (23). Another study found that children with $50 \mathrm{nmol} \leq 25(\mathrm{OH})$ $\mathrm{D}_{3}<75 \mathrm{nmol} / \mathrm{L}$ before delivery have a lower risk of asthma at 4 years old than those born to mothers with less than $50 \mathrm{nmol} / \mathrm{L}$ (24). However, most studies have not found a significant association between maternal prenatal vitamin levels and childhood asthma $(13,15,25,26)$, which may be related to the difference in risk detection ability and the small sample size of each study. Chawes et al. (27) found that children with a cord blood $25(\mathrm{OH}) \mathrm{D}$ concentration $<50 \mathrm{nmol} / \mathrm{L}(\mathrm{n}=136)$ had a higher risk of asthma than those with a concentration $>75 \mathrm{nmol} / \mathrm{L}(\mathrm{n}=39)(\mathrm{OR} 1.60)$, but the difference was not statistically significant $(95 \%$ CI: 0.49-5.22). Another report showed that compared to newborns with $<30 \mathrm{nmol} / \mathrm{L}$ in the third trimester, newborns with $25(\mathrm{OH}) \mathrm{D}>75 \mathrm{nmol} / \mathrm{L}$ had an increased risk of spring asthma at 9 years of age (28). This was contrary to the findings of our study, which may be related to the small sample size of the study (19 cases), or it may be related to the $25(\mathrm{OH}) \mathrm{D}$ measurement method and time, the definition of asthma, age at diagnosis, study design, or the applied statistical analysis. In addition, these studies were conducted in different populations at different time points, and the follow-up time was different. The combined analysis of two randomized controlled trials found that taking vitamin D supplements before childbirth significantly reduced the risk of asthma at age 3 (OR $=0.74,95 \%$ CI: $0.57-0.96$ ), but there was no significant difference in long-term risk (at age 6) $(\mathrm{OR}=1.21,95 \% \mathrm{CI}: 0.63-2.32)(29,30)$. This may be related to the difference in the definition of age interval or asthma in the analysis method.

This study found for the first time a clear correlation between neonatal vitamin $\mathrm{D}$ levels and the risk of asthma in 
children aged 3-9 years. In this study, DBSS measurement instead of plasma or serum measurement was used, the measurement of $25(\mathrm{OH}) \mathrm{D}$ concentration was more accurate and effective, and this study used a uniformly diagnosed asthma history in the medical record system, therefore, the diagnosis was true and reliable. However, this study also had certain shortcomings. First, this study failed to include additional maternal information, such as obesity and more chronic disease information when adjusting for confounding factors. Secondly, the DBSS measurement of $25(\mathrm{OH}) \mathrm{D}_{3}$ has certain threshold requirements, and it has a certain correction effect for $25(\mathrm{OH}) \mathrm{D}_{3}$ outside the threshold.

In summary, there is a significant correlation between reduced vitamin $\mathrm{D}$ levels in newborns and the risk of childhood asthma at the age of 3-9 years, and the level of Vitamin D is an independent risk factor for childhood asthma. Early recognition of neonatal vitamin levels and intervention is of great significance for the prevention of childhood asthma.

\section{Acknowledgments}

Funding: None.

\section{Footnote}

Reporting Checklist: The authors have completed the MDAR checklist. Available at http://dx.doi.org/10.21037/tp-21-92

Data Sharing Statement: Available at http://dx.doi. org/10.21037/tp-21-92

Conflicts of Interest: All authors have completed the ICMJE uniform disclosure form (available at http://dx.doi. org/10.21037/tp-21-92). The authors have no conflicts of interest to declare.

Ethical Statement: The authors are accountable for all aspects of the work in ensuring that questions related to the accuracy or integrity of any part of the work are appropriately investigated and resolved. All procedures performed in this study involving human participants were in accordance with the Declaration of Helsinki (as revised in 2013). Parental informed consent was obtained on behalf of all subjects and the study was approved by the Research Ethics Committee of Haikou Hospital of The Maternal And Child Health.
Open Access Statement: This is an Open Access article distributed in accordance with the Creative Commons Attribution-NonCommercial-NoDerivs 4.0 International License (CC BY-NC-ND 4.0), which permits the noncommercial replication and distribution of the article with the strict proviso that no changes or edits are made and the original work is properly cited (including links to both the formal publication through the relevant DOI and the license). See: https://creativecommons.org/licenses/by-nc-nd/4.0/.

\section{References}

1. Lai CK, Beasley R, Crane J, et al. Global variation in the prevalence and severity of asthma symptoms: phase three of the International Study of Asthma and Allergies in Childhood (ISAAC). Thorax 2009;64:476-83.

2. Drever N, Saade GR, Bytautiene E. Fetal programming: Early-life modulations that affect adult outcomes. Curr Allergy Asthma Rep 2010;10:453-9.

3. Just J, Saint Pierre P, Amat F, et al. What lessons can be learned about asthma phenotypes in children from cohort studies? Pediatr Allergy Immunol 2015;26:300-5.

4. Yung JA, Fuseini H, Newcomb DC. Hormones, sex, and asthma. Ann Allergy Asthma Immunol 2018;120:488-94.

5. Salle BL, Delvin EE, Lapillonne A, et al. Perinatal metabolism of vitamin D. Am J Clin Nutr 2000;71:1317S-24S.

6. Saraf R, Morton SM, Camargo CA Jr, et al. Global summary of maternal and newborn vitamin D status - a systematic review. Matern Child Nutr 2016;12:647-68.

7. Baca KM, Simhan HN, Platt RW, et al. Low maternal 25-hydroxyvitamin D concentration increases the risk of severe and mild preeclampsia. Ann Epidemiol 2016;26:853-7.e1.

8. Zhang MX, Pan GT, Guo JF, et al. Vitamin D Deficiency Increases the Risk of Gestational Diabetes Mellitus: A Meta-Analysis of Observational Studies. Nutrients 2015;7:8366-75.

9. Keller A, Stougård M, Frederiksen P, et al. In utero exposure to extra vitamin $\mathrm{D}$ from food fortification and the risk of subsequent development of gestational diabetes: the D-tect study. Nutr J 2018;17:100.

10. Feng H, Xun P, Pike K, et al. In utero exposure to 25-hydroxyvitamin D and risk of childhood asthma, wheeze, and respiratory tract infections: A metaanalysis of birth cohort studies. J Allergy Clin Immunol 2017;139:1508-17.

11. Pfeffer PE, Mann EH, Hornsby E, et al. Vitamin D 
influences asthmatic pathology through its action on diverse immunological pathways. Ann Am Thorac Soc 2014;11 Suppl 5:S314-21.

12. Chawes BL, Bønnelykke K, Stokholm J, et al. Effect of Vitamin D3 Supplementation During Pregnancy on Risk of Persistent Wheeze in the Offspring: A Randomized Clinical Trial. JAMA 2016;315:353-61.

13. Litonjua AA, Carey VJ, Laranjo N, et al. Effect of Prenatal Supplementation With Vitamin D on Asthma or Recurrent Wheezing in Offspring by Age 3 Years: The VDAART Randomized Clinical Trial. JAMA 2016;315:362-70.

14. Wolsk HM, Chawes BL, Litonjua AA, et al. Prenatal vitamin D supplementation reduces risk of asthma/ recurrent wheeze in early childhood: A combined analysis of two randomized controlled trials. PLoS One 2017;12:e0186657.

15. Chawes BL, Bønnelykke K, Jensen PF, et al. Cord blood 25(OH)-vitamin D deficiency and childhood asthma, allergy and eczema: the COPSAC2000 birth cohort study. PLoS One 2014;9:e99856.

16. Hennessy Á, Hourihane JO, Malvisi L, et al. Antenatal vitamin $\mathrm{D}$ exposure and childhood eczema, food allergy, asthma and allergic rhinitis at 2 and 5 years of age in the atopic disease-specific Cork BASELINE Birth Cohort Study. Allergy 2018;73:2182-91.

17. Gale CR, Robinson SM, Harvey NC, et al. Maternal vitamin D status during pregnancy and child outcomes. Eur J Clin Nutr 2008;62:68-77.

18. Morales E, Romieu I, Guerra S, et al. Maternal vitamin $\mathrm{D}$ status in pregnancy and risk of lower respiratory tract infections, wheezing, and asthma in offspring. Epidemiology 2012;23:64-71.

19. Pedersen CB. The Danish Civil Registration System. Scand J Public Health 2011;39:22-5.

20. Schmidt M, Schmidt SA, Sandegaard JL, et al. The Danish National Patient Registry: a review of content, data quality,

Cite this article as: Li W, Zhou J, Liu S, Xing K, Yang L, Zhong L, Chen Q, Zhang W. The correlation between neonatal vitamin $\mathrm{D}$ levels and the risk of childhood asthma attacks. Transl Pediatr 2021;10(4):914-920. doi: 10.21037/tp-21-92 and research potential. Clin Epidemiol 2015;7:449-90.

21. Nørgaard-Pedersen B, Hougaard DM. Storage policies and use of the Danish Newborn Screening Biobank. J Inherit Metab Dis 2007;30:530-6.

22. Eyles DW, Morley R, Anderson C, et al. The utility of neonatal dried blood spots for the assessment of neonatal vitamin D status. Paediatr Perinat Epidemiol 2010;24:303-8.

23. Bodnar LM, Catov JM, Wisner KL, et al. Racial and seasonal differences in 25-hydroxyvitamin $\mathrm{D}$ detected in maternal sera frozen for over 40 years. Br J Nutr 2009;101:278-84.

24. Chiu CY, Huang, SY, Peng YC, et al. Maternal vitamin $\mathrm{D}$ levels are inversely related to allergic sensitization and atopic diseases in early childhood. Pediatr Allergy Immunol 2015;26:337-43.

25. Bliddal M, Broe A, Pottegård A, et al. The Danish Medical Birth Register. Eur J Epidemiol 2018;33:27-36.

26. Martinez FD, Wright AL, Taussig LM, et al. Asthma and wheezing in the first six years of life. The Group Health Medical Associates. N Engl J Med 1995;332:133-8.

27. Chawes BL, Bønnelykke K, Jensen PF, et al. Cord blood 25(OH)-vitamin D deficiency and childhood asthma, allergy and eczema: the COPSAC2000 birth cohort study. PLoS One 2014;9:e99856.

28. Gale CR, Robinson SM, Harvey NC, et al. Maternal vitamin $\mathrm{D}$ status during pregnancy and child outcomes. Eur J Clin Nutr 2008;62:68-77.

29. Gray RJ. Weighted analyses for cohort sampling designs. Lifetime Data Anal 2009;15:24-40.

30. Vasiliou JE, Lui S, Walker SA, et al. Vitamin D deficiency induces Th2 skewing and eosinophilia in neonatal allergic airways disease. Allergy 2014;69:1380-9.

(English Language Editor: D. Fitzgerald) 